\title{
Effectiveness of Foreign Philanthropy Campaign and Relation with Inner Interactions in Transnational Co-Operative Organization
}

\author{
Wei Lo', Sophia Huang ${ }^{2}$ and Jersan $\mathrm{Hu}^{3}$ \\ ${ }^{1}$ Associate Professor, Guangxi University of \\ Finance and Economics \\ 2Ph.D. candidate, Fu Jen Catholic University \\ ${ }^{3}$ Chair of Taiwan Social Enterprise Society \\ sophia2077@gmail.com
}

\begin{abstract}
It is of necessity for developed economic societies to provide philanthropic services to the societies of neighboring countries. Developed societies have resource and capacity advantages in terms of knowledge technology and organizational strength; thus, it is imperative that they provide adequate supports to the comparatively more vulnerable societies. However, due to insufficient in-depth understanding to the local socio-economic structure, work mentality and value, technology capacities, and resource condition of the local societies (or social groups), the philanthropic target and local social value often come into cognitive conflicts in the process of collaboration which ultimately affect the bilateral resource integration and effectiveness of application. The study, based on the researchers' venture in the household water purification project in rural Vietnam villages, employed action research method to confirm the cognitive gap on philanthropy, the expectation deviation on work mission, and the action deviation effect of the organizational cultures on transforming philanthropic service into philanthropic entrepreneurship encountered in the process of executing the philanthropic projects by transnational cooperative teams in the two-year overseas services.

Keywords: social enterprise, social entrepreneurship, social resource, transnational philanthropic campaign

JEL : M14

DOI $\quad: 10.24002 /$ kinerja.v22i2.3229

Received : 10/18/2019 Reviewed: 10/29/2019 Final Version: 01/29/2019
\end{abstract}




\section{INTRODUCTION}

In the past years, this research team has not only been conducting in-depth study on the international social enterprise cases to promote social enterprise theories and actions, but also actively engaging in social services and even social entrepreneurship consulting. From the consulting process, the team acquired the concepts of the social entrepreneurs' mentality, resource utility, and management design; in addition, the team explored the problems the social enterprises encountered in inner cross-cultural (enterprise culture vs. social philanthropic culture) adaptation issues.

To expand the capacity tests of Taiwan social entrepreneurs and to explore cross-cultural social adaptation issues, the study selected the "international society engagement" project the researchers have engaged in. The case project is a philanthropic service of household water purification in Bac Nin, Vietnam. The twoyear social improvement project in Vietnam not only helps Taiwanese youth proactively enhanced international social service experience, but also confirms their own understanding on international societies and degree of control over cooperation action. In the process of confirming the obstacles lie in cross-border cooperation and local problems solving, they understand the impact of crosscultural differences on local philanthropic entrepreneurship.

\subsection{Research theme}

In 2014, the lead author actively promoted and engaged in the project of "Household Water Purification Campaign in Bac Nin, Vietnam". A total of four preceding community visits and exchanges were conducted since the first contact of the case project, to set it as the service target and to actually dispatch the service team consists of both faculty members and students. From the on-site observation and communication, the team hoped to confirm the nature of the community problems, e.g., the cause of the problem, the service items required, service planning, and the orientation in Taiwan, including preparatory operation and building service groups organizing system in Taiwan. The preparatory stage took one year and the fifth visit took one month to carry out the service activities. The unexpected scenarios encountered in the period, like the planning oversight, execution flaw, and the failure of the local organizations in completing the predelivered tasks, made the considered well-planned project with teams adequately trained still encountered many bilateral obstacles and required on-sight adaptations.

The research extended from 2014 to 2016 with a total of nine visits of the team members to execute the project. An overall review of the project effectiveness showed that although it is within the capacity (both technical and competence) of Taiwanese youth to provide social philanthropic services to the neighboring countries, in the progress of handling bilateral expectation on target, action items, and resource coordination, there are several phenomena which affect the effectiveness of the cooperation and integration of the bilateral organizations. 
These phenomena include: insufficient understanding on the structure of local society (social groups), local cultural mentality and value, and local technology capacities and resource conditions, which led to cultural adaptation, technology adjustment, and cognition inconsistency in goal setting and social value in bilateral communications and interactions.

Through the experience gained in this transnational philanthropic campaign engagement, the study aims to build a strategic process of transforming transnational philanthropic campaign into transnational entrepreneurship and explore the challenges in the translational actions, such as the execution capacity of translational collaboration team in philanthropic projects, the gap in philanthropic cognition and the expectation gap on work mission of the bilateral teams, and the deviation of resource expectation.

\subsection{Research purpose}

Through practical engagement in the social improvement activities of a foreign society, the study documented the progress of the service activities, related social organizational behaviors, and the onset of various conflicts and cooperation in action. In the theoretical aspect, the study focuses on exploring how the uphold concepts in the bilateral organizational interaction and the differences in social organizational structure affect the integrative application of cooperative resources and the progress of philanthropic affairs. In practice, the study provides the necessary conceptual enhancement and changes in interaction attitude for the increasing transnational philanthropic activities.

\section{LITERATURE REVIEW}

\subsection{Transnational economies and social gaps affect the international affairs' response to globalization}

The international society members are like a small society when they face the issues of global concern; they also face the predicaments of "international government" failure, the disproportion of resource capacity among the member states, and the "merits offset faults" of the multinational enterprises in local countries. In short, the gaps among countries led to un-implementation in reality, the uneven development, and unjust of global universal value or philosophy let alone individual countries bearing the same "international" social responsibilities and obligations. Due to the economic and social gaps between countries, the international philanthropic services, in which the international charitable relief actions and non-profit organization participated, will occur in response to the needs of the respective countries.

Ghemawat (2014) believed that to effectively solve the social and environmental problems of globalization, it is necessary to adopt a pragmatic attitude and based on the political, economic, cultural, and geographic gaps of the 
respective countries, put the perspectives and solutions of the problems into regional, national, and local levels and adopt the solutions appropriate to the capacity of particular geographic region and national condition. In examining global social issues, there exists the deviation of value and the nature of problem, which warrant various approaches in handling social issues, either by global standards or regional adaption.

There are five modes of interaction for transnational affairs between countries: devolution, distance-sensitivity, distance-directedness, distinctive-competence, and de-biasing (Ghemawat, 2014).

1. Devolution emphasizes that only 10 to $20 \%$ of the national and international social and commercial interactions are globalized. The majority of the remaining interactions are of transnational or regional nature.

2. Distance-sensitivity refers to even the shared concerns on economic and social issues require international coordination mechanism, the higher the distance-sensitivity, the more it is inclined to appeal to sub-global, or even regional or sub-regional arbitration. Thus, in handling globalization affairs, we cannot rely solely on the intuition of the geographical location of a country, but also include the conditions like economic level, cultural characteristics, national policy and administrative management, and geographic location to more accurately remapping the world to demonstrate the interaction, similarity, and even mutual dependence between countries.

3. Distance-directedness: The distance between the countries reveals the core location of international affairs activity ("where"), whom and what to negotiate with ("what"), and how to integrate the related countries to effectively handle international affairs ("how"), which serve as a basis for judgment and handling of global affairs.

4. Distinctive-competence: The unique advantage and competence an international organization or country possesses is another capacity that help a nation decide if it is worthwhile to promote or how to deal with certain international agendas.

5. De-biasing: Many countries are still rather skeptical and distrustful towards foreign or international interactions. The international affairs advocates should endeavor in building reciprocity and mutual trust between countries and avoid showing pride and neglecting the inherent knowledge and capacity of the recipient country.

In short, the deviation between countries is an important element to be placed under consideration in handling international affairs. The deviation may trigger perception gaps on work, capacity gaps, and administrative jurisdiction range, etc., which may affect the effectiveness of transnational philanthropic campaigns. 


\subsection{Transnational philanthropic and philanthropic entrepreneurship}

NGOs provide voluntary welfare and services. Their core spirit lies in creating and disseminating the value for vulnerable groups on an altruistic principle. Thus, the NGOs action to some extent compensates local government failure and market failure. However, NGOs themselves also face the control issues of scarce resource, administrative management, and the uncertainty of external environment, which lead to the dire predicaments of not blending into local scenarios to solve the problems. In short, NGOs are limited to their own resources; it is necessary for them to collaborate with the government or businesses to help each other in achieving the respective social goals.

Due to the constraints on funding access, when NGOs develop social services or community public affairs, their effectiveness is often baffled. Even they can receive financial infusion, without sufficient resource planning, NGOs still often failed to fully play their due diligence and expand their influence due to lack of professional techniques, manpower, or management capacities. In Europe and UK, NGOs and charity institutions are encouraged to blend their social service activities with commercial operation and include entrepreneurship into the world of philanthropy; thus emerged the concept of "venture philanthropy/philanthropic entrepreneurship" or "philanthropreneurship" (Wagner, 2002). Letts and Grossman (1997) believed that when sponsorship foundations participate in the NGO service activities, in addition to granting funds, they can employ the models of commercial entrepreneurship and provide commercial technology support or engage in the management operation.

\subsection{International philanthropreneurship process, strategic transformation, and entrepreneurial models}

Social enterprise as a concept first appeared in 1994 OECD report. It defined social enterprise as an organization which utilizes market resources and nonmarket resources to offer low-skill workforce return to the job market. Also gave detailed description on social enterprise is any private activity conducted in the public interest, organized with an entrepreneurial strategy, but whose main purpose is not the maximization of profit but the attainment of certain economic and social goals, and which has the capacity for bringing innovative solutions to the problems of social exclusion and unemployment (OECD, 2002). Then the movement of social entrepreneurship in NPO society also described as "combining commercial enterprises with social impacts". In this perspective, entrepreneurs have used business skills and knowledge to create enterprises that accomplish social purposes in addition to being commercially viable (Emerson and Twersky, 1996; Prahalad \& Hammond, 2002).

Social exclusion is that certain social groups are placed in a vulnerable social condition due to political, economic, social, and cultural factors and the process of been excluded from the social norms. The uniqueness of social exclusion concept is that it focuses mainly on the issue of social connections, i.e., lack of social 
engagement, lack of social integration, and lack of power (Room, 1998). The most significant feature of social exclusion theory is that it transcends conventional and specific material needs and emphasizes the importance of social connections in the provision of social welfare. In other words, the social exclusion theory provides a new lens on the content and scope of social welfare. In response to the issue of social exclusion, fulfilling the social needs of the vulnerable groups, the capacity building of the individual, and the empowerment of the vulnerable groups have become the vital elements in social welfare provision (Sen, 1993). The exploration on the non-market demands is the in-depth clarification on the phenomenon of social exclusion.

\subsection{The inner conflicts in the process of social entrepreneurship}

After the individuals with entrepreneur spirits have a fully understanding of social exclusion phenomena, equipped with the concepts for solutions and confidence, often the individuals would devote themselves into actions and contemplate on the strategies on organizational sustainability. Guclu, Dees, \& Anderson (2002) believed that there are two phrases in social entrepreneurship endeavors. The first phrases is "to make commitment", the other is "to develop opportunities for profit." Even in the making commitment phrase, the concept of social entrepreneurship doesn't just occur randomly; it takes the a priori social experiences of the entrepreneurs to recognize social needs, the social assets that can be employed to problem solving, and the innovative concept of promoting social change to deliver a balanced thinking in valuing social needs and solution capacity.

The second phrase values the logic of transforming a commitment into putting social value in practice and takes a further step in designing operation model and management strategies. The social entrepreneurship Bornstein (2007) recognized is a power to transform: "Those who uphold new concepts on social issues vigorously pursue their vision; they never said 'no' in their reply and relentlessly promote their ideas and never give up easily." However, in addition to a strong sense of social mission and entrepreneurship, it calls for practical entrepreneurial actions and design thinking on business systems.

From the encountered integration of social concepts and corporation skills in the process of entrepreneurship, what can be observed are the unavoidable inner ideology conflicts of the organizations. This is the integration strategies of transnational philanthropic campaigns this study intends to explore through the inner dynamics of the transnational operational and delivery organizations.

\section{METHODOLOGY}

This study employs action research design, taking the practical case the research team engaged in as the research subject, using the on-hand experience of the team members as the data basis, and employing the plan upheld by the 46 
philanthropic action as the proposed theoretic framework. The study constantly detects and reviews the challenges encountered during the operation and policy adjustment made accordingly to gradually practice the action research of "internal relationship of transnational philanthropic entrepreneurship" with learning improvement function (Susman, 1983).

\subsection{Subjects}

The study first began from July to August, 2014 when the invitation by the parish bishop of Bac Nin, Vietnam brought the researchers into the rural villages in northern Vietnam. The village $\mathrm{Tu} \mathrm{Ne}$ was finally selected and the improvement of household water, the vital resource to the villagers, was decided to be the target of the project. After confirming the project and the target, the team members made several trips on site, not only inviting Taiwan experts to conduct in-depth field survey of the causes of river contamination, but also confirming the local villagers' consensus on accepting changes. The voluntary team from Taiwan then landed in $\mathrm{Tu} \mathrm{Ne}$ nine times, from 2015-2016, to work on the river water purification construction. A total of 23 members participated in this project. This study takes the collaborative interaction of Taiwan team and Vietnam local team as the research subject.

\subsection{The original concept of the research plan}

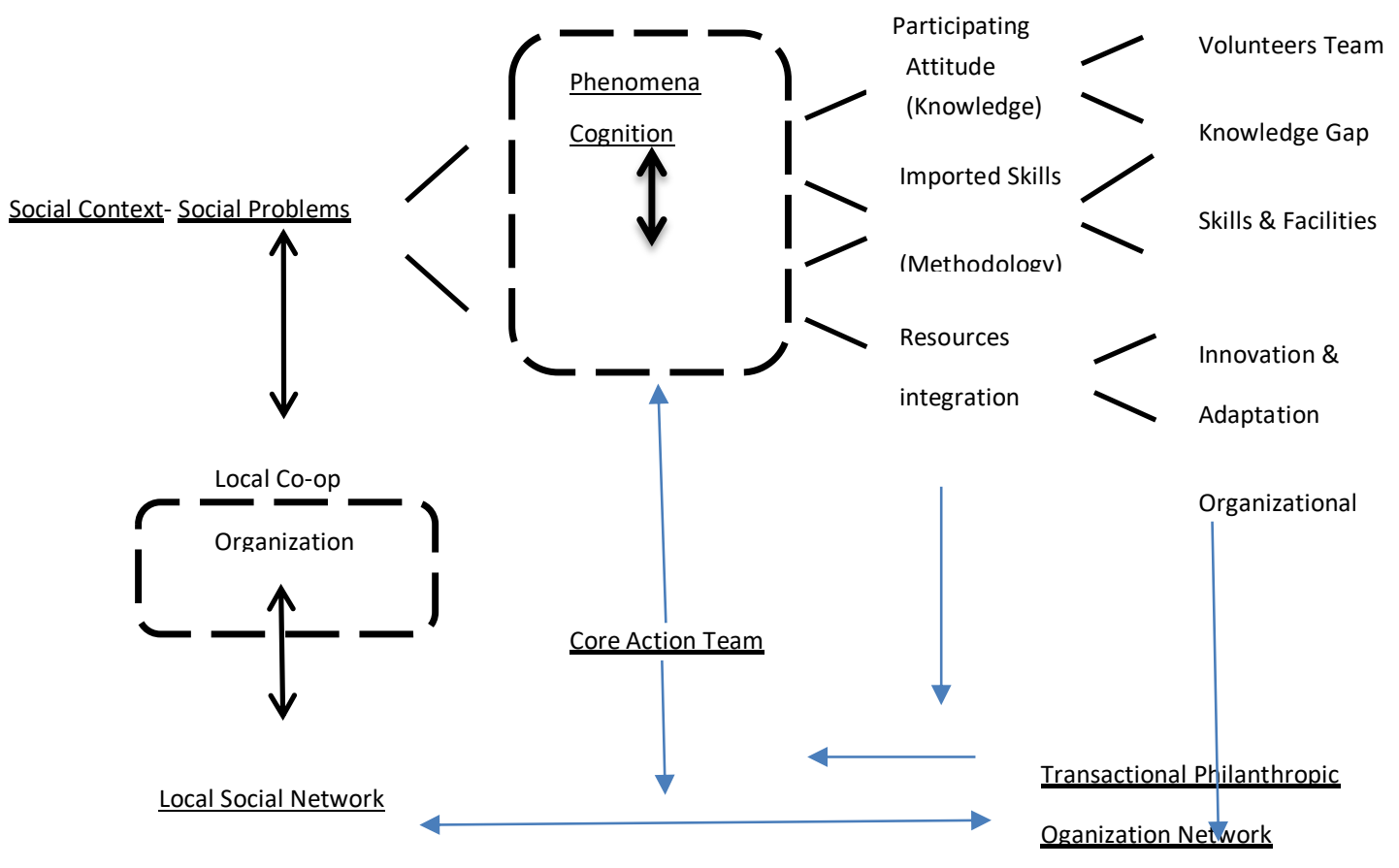

Figure 1. The interactive relationship framework of the transnational philanthropic entrepreneurship collaboration teams 
Prior to the launch of collaboration action, the team educated, with an attitude of pluralism, the members to localize their thinking and experience and design the applicable solutions to the local characteristics and socio-economic conditions, which include the mentality of the actors, the invested technology and the resource integration. The Taiwan voluntary team is then organized and the members are provided with orientation training, necessary equipment, and resource adjustment.

\subsection{Data collection}

As the team members planned and led the philanthropic operation, the research project owns the authentic research data of all forms and sources in the process, including:

1. completely participating observation

2. experiencing

3. working meeting records

4. photographs

\section{FINDINGS}

\subsection{The connection between international philanthropic groups and local social groups}

The Taiwan team found that pollution issue of the river water, the household water source of the case village, is completely alien from the home experience of Taiwan team. Thus, it is necessary for the team to shift the mentality and completely blend into the local environment, re-explore the social phenomena, like local geography, humanities, and living styles, etc. to engage Taiwan experts and community members in finding the solutions.

1. The solutions for overseas community problems require full understanding of the community culture, social inheritance, and geographic constraints, i.e., local mentality. To have an in-depth understanding of the local social issue from the perspective of local mentality, we must face the social structure, the existing material conditions, and the unsatisfied needs of the local communities, which are the situational conditions of social problems.

2. An action core is imperative when an international philanthropic group evaluates how to connect with and confirm the social issues of a specific overseas community and decides to help solve the problems with overseas resources. The core must possess a higher knowledge level and adopt the social methodology which respects the local context to coordinate the inputs of all parties, formulate the solutions appropriate to the local situations, strive for overseas and local resources, and design action plan.

3. Based on the action plan, the core organization first seeks volunteers, financial and physical equipment supports from the home country or 
international communities. In the process of problem solving, when encountered obstacles, the organization must adjust the perceptions and technology, or even change the existing knowledge and concepts.

Figure 2 illustrates the above three points. The connecting relationship the international philanthropic campaign organizations have with local social structure affects the international team's comprehension depth of the local social problem and the role they play in the international collaborative interaction (the directive or participative attitude) and further influences their degree of acceptance of local mentality or life technology. The lower the degree of acceptance, the lower the levels of local adaptability, cross-cultural coordination, and social innovation of philanthropic actions.

In the initial stage, the Taiwan team's mentality in interaction was more selfcentered and directive in nature. With the onset of interaction barriers, the team began to appreciate the value of local conditions and technology adaptability.

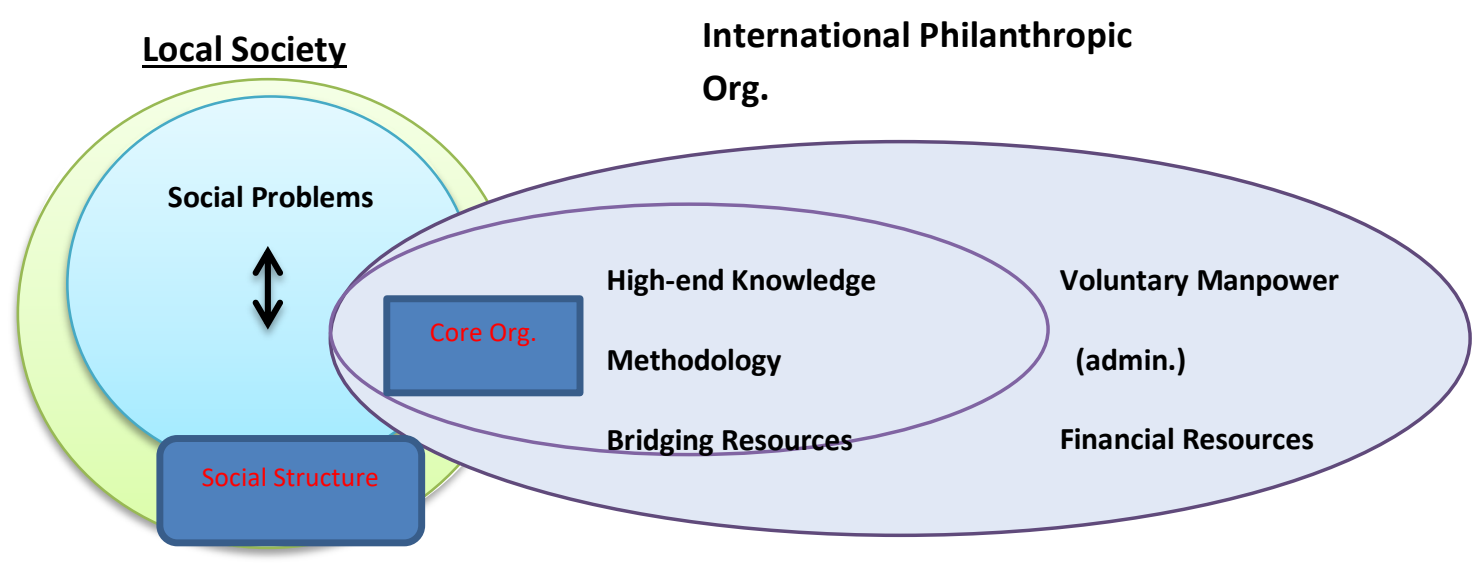

Figure 2. The ideal interaction model for international philanthropic team and local team

\subsection{The cultural factors affecting transnational philanthropic cooperative action}

\subsubsection{The dynamics in the core of team}

Cross-border organizations possess superior knowledge, international experience, modern life skills, and overseas financial capacities. Naturally, in a transnational collaboration team, they would have a stronger voice and leadership, which can be regarded as the "core" of transnational collaboration organization. They have the absolute impact on the decision-making and the operation and delivery of the collaborative organizations. Thus, the differences in the mentality the core organization holds, be it self-centered perceptions (modernism), accepting the culture of local organization from the own scientific perceptions 
(postmodernism), or perceptions that completely absorb and draw on local concept (pluralism), determine the interactivity of the inner culture of transnational collaborative organizations.

To weigh the problems and select the solutions in local or extrinsic mentalities is the selection difference in the sociology knowledge of transnational culture, modernism, postmodernism, or pluralism. During the joint actions of transnational organizations, it influences the cognitive depth on the problem, the knowledge base of thinking, or even the design of solutions. This sociological knowledge perception on cross-culture is an important factor that influences the operation of cross-cultural collaborative organizations.

Similarly, the knowledge mindset of the action core affects the organizations' selection of the three scientific technologies: generalized technology, adaptation of generalized technology, or completely domestic technology.

Being confident in the resource and capacity they own, the international philanthropic organizations with higher international general technology and knowledge often ignore the adaptability of local knowledge, the inherent technology and resource conditions of the local organizations. This knowledge mindset of social science naturally influences the technology and knowledge selection in the cross-border philanthropic action design and often leads to problems of local adaptability.

\subsubsection{The capacity training and inheritance of transnational collaborative organizations}

The knowledge theory and methodology perspectives of action core influence the depth of local infiltration and the breadth of adopting local resource. The less the local infiltration, the fewer local resources will be used, leading to heavier dependence on foreign knowledge, technology, and manpower. Meanwhile, the role of being a bridge between the local social network and international philanthropic groups the action core play would be different. This discrepancy may lead to the mutual trust issue of the transnational organization because the action core was designed to be responsible for weighing the collaboration and connection of transnational resources and technical manpower.

\subsubsection{Local social integration and social entrepreneurship opportunities of transnational collaborative organizations}

The action core builds the transnational resource network of specific social issue as the subject. In the process of action, international volunteers join the action plan equipped with their own professional knowledge, experience, and social status. They demonstrate their group status and functional position in the philanthropic team, not only changing the power hierarchy of international volunteers, but also affecting their understanding of and respect to local societies and the mode of interaction. These all contribute to the various degree of alienation in their interaction with the local resource networks. 
Mode I Relation structure of philanthropy bridging failure

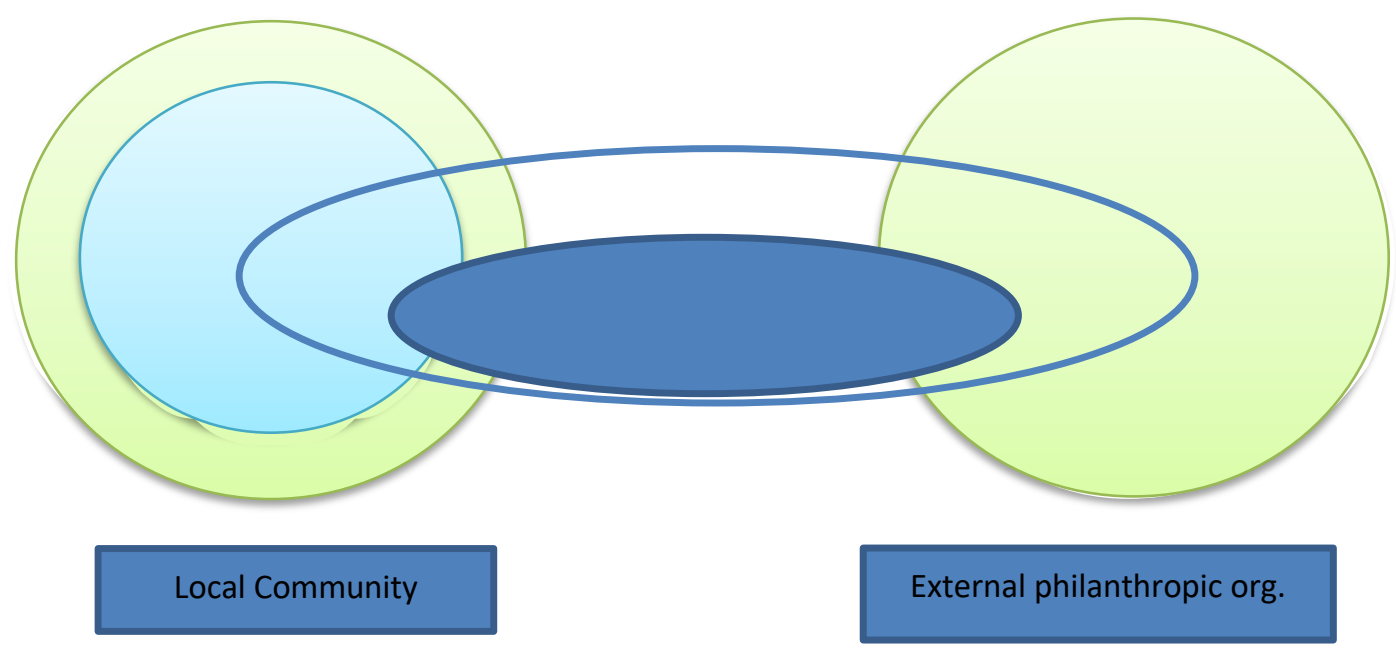

Mode $\amalg$ The separation structure of philanthropic and local organizations

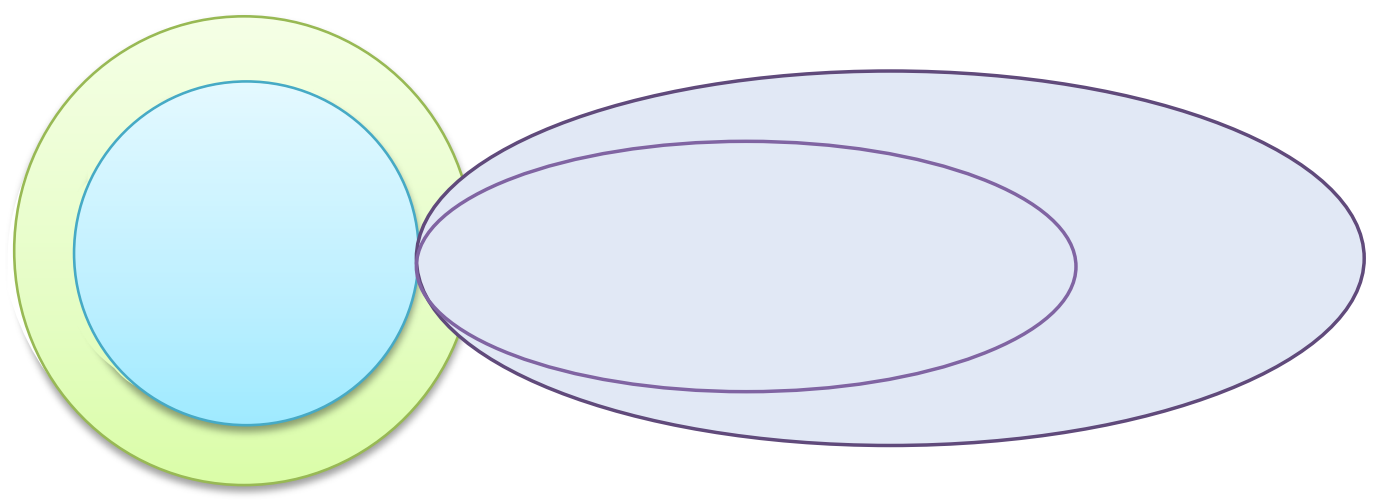

Mode II Relation structure of philanthropic groups separation

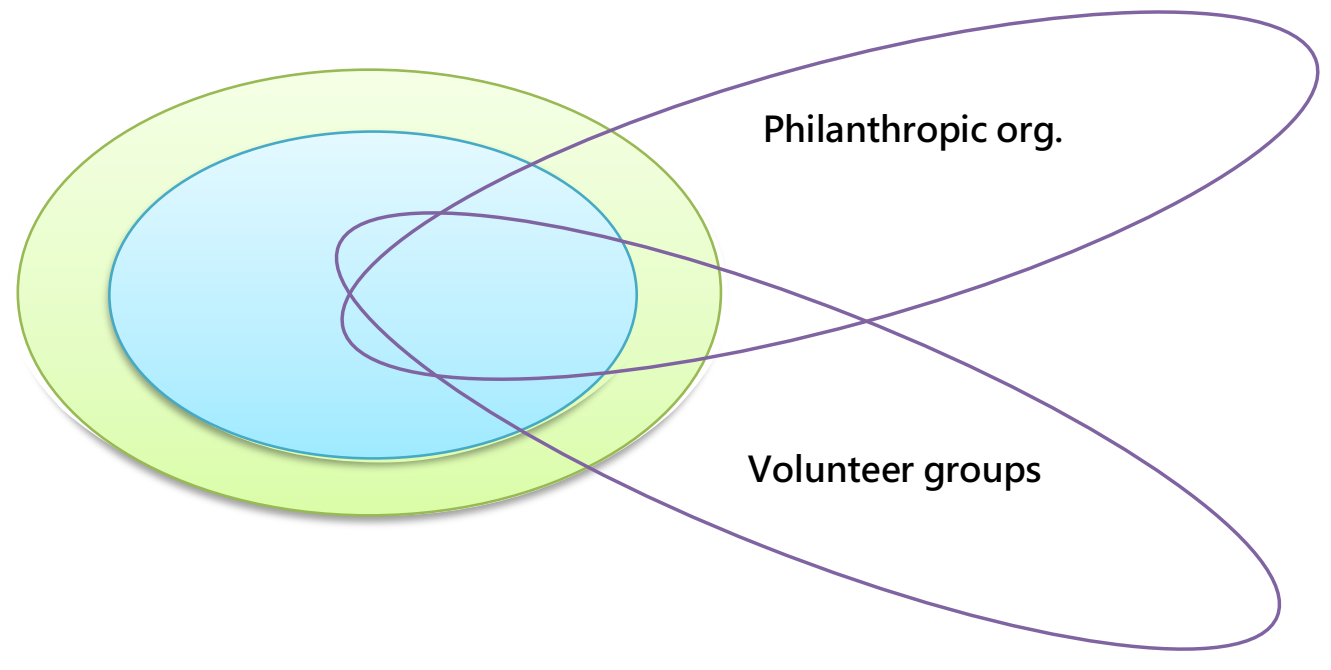




\section{Mode IV Relationship structure of exploiting philanthropy}

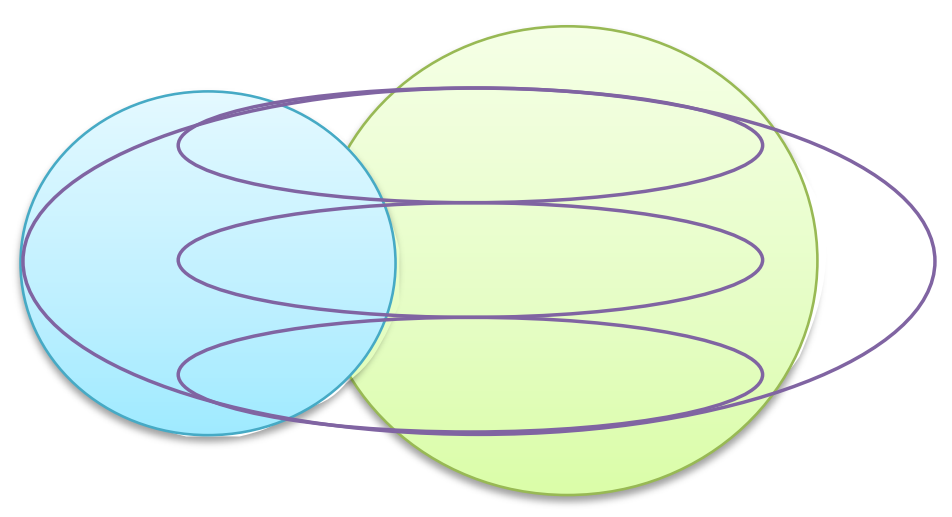

Figure 3. The interaction mode of transnational philanthropic group and local groups ideal mode and actual deviation mode

Table 1. Conceptual gaps between local organization and foreign organization

Variables Local org. concepts Foreign org. concepts Conceptual gaps

\begin{tabular}{|c|c|c|c|}
\hline $\begin{array}{l}\text { "Problem } \\
\text { cognition"- } \\
\text { presentation }\end{array}$ & $\begin{array}{l}\text { We have water issue. } \\
\text { They (foreign } \\
\text { experts, rich people) } \\
\text { are coming to help us } \\
\text { solve the problem. }\end{array}$ & $\begin{array}{l}\text { We have org. mission. Need } \\
\text { to find a mission that is much } \\
\text { sought and within our } \\
\text { capacities. }\end{array}$ & $\begin{array}{l}\text { Int'l org. value the } \\
\text { org. mission and } \\
\text { resource constraints; } \\
\text { local org. emphasizes } \\
\text { solving practical } \\
\text { issues. }\end{array}$ \\
\hline $\begin{array}{l}\text { "Problem } \\
\text { cognition" - } \\
\text { problem } \\
\text { structure }\end{array}$ & $\begin{array}{l}\text { This is a big } \\
\text { community issue that } \\
\text { costs money; it } \\
\text { needs local } \\
\text { consensus and } \\
\text { assistance; } \\
\text { multilateral } \\
\text { coordination and } \\
\text { communication is } \\
\text { necessary. }\end{array}$ & $\begin{array}{l}\text { This is an overseas project. It } \\
\text { needs to meet social } \\
\text { philanthropic concept and } \\
\text { complete adapted technology } \\
\text { transfer, and fully exploit } \\
\text { local design. }\end{array}$ & $\begin{array}{l}\text { Local org. focuses on } \\
\text { local people's } \\
\text { reactions and finance } \\
\text { issue; int'l org. } \\
\text { focuses on "social } \\
\text { benefits and } \\
\text { community } \\
\text { adaptation." }\end{array}$ \\
\hline $\begin{array}{l}\text { "Role } \\
\text { cognition" }\end{array}$ & $\begin{array}{l}\text { We're poor and } \\
\text { backward; they have } \\
\text { the abundant support } \\
\text { from private firms. } \\
\text { When they come to } \\
\text { "help" us, they should } \\
\text { bring what we need } \\
\text { the most: money, } \\
\text { materials, and } \\
\text { technology. }\end{array}$ & $\begin{array}{l}\text { We're better equipped with } \\
\text { knowledge and should help } \\
\text { according to plan step by } \\
\text { step. They should just follow } \\
\text { our plan and accommodate } \\
\text { our time allocation. They } \\
\text { should also provide adequate } \\
\text { financial and manpower } \\
\text { inputs to show their local } \\
\text { determination for } \\
\text { improvement. }\end{array}$ & $\begin{array}{l}\text { Both parties expect } \\
\text { the other to have } \\
\text { more resource input } \\
\text { and ignore their own } \\
\text { resource constraints. } \\
\text { Both parties have a } \\
\text { sense of distrust on } \\
\text { the other. } \\
\text { Expect each other to } \\
\text { demonstrate their } \\
\text { sincerity and strength. }\end{array}$ \\
\hline
\end{tabular}


(Wei Lo, Sophia Huang and Jersan Hu)

\begin{tabular}{|c|c|c|c|}
\hline $\begin{array}{l}\text { "Solution } \\
\text { design and } \\
\text { financial } \\
\text { dependence" }\end{array}$ & $\begin{array}{l}\text { We have poor living } \\
\text { condition. When you } \\
\text { come to help us, you } \\
\text { should provide } \\
\text { environment facilities } \\
\text { that meet our daily } \\
\text { demand, not obsolete } \\
\text { technology. }\end{array}$ & $\begin{array}{l}\text { We should try to localize and } \\
\text { try local lifestyle and } \\
\text { consuming pattern; therefore, } \\
\text { the costs shouldn't be too } \\
\text { high. } \\
\text { Design budgets based on the } \\
\text { financial strength of the other } \\
\text { party. }\end{array}$ & $\begin{array}{l}\text { There are } \\
\text { assumptions on the } \\
\text { counter party's } \\
\text { willingness in } \\
\text { financial expenses. In } \\
\text { fact, the financial } \\
\text { strength is not related } \\
\text { to the budget of } \\
\text { technology used. }\end{array}$ \\
\hline $\begin{array}{l}\text { Mission } \\
\text { target } \\
\text { cognition }\end{array}$ & $\begin{array}{l}\text { You rush to start the } \\
\text { work upon arrival; we } \\
\text { have our own life to } \\
\text { live; we need to } \\
\text { consider the overall } \\
\text { environment and the } \\
\text { villagers. We can't } \\
\text { accommodate your } \\
\text { pace at your will. }\end{array}$ & $\begin{array}{l}\text { We have the constraints on } \\
\text { time and resource. We have } \\
\text { everything all carefully } \\
\text { planned out and came well- } \\
\text { prepared. We just want to } \\
\text { complete the mission } \\
\text { accordingly and efficiently. } \\
\text { Why are you so inefficient? }\end{array}$ & $\begin{array}{l}\text { The local org. are } \\
\text { affected by local } \\
\text { social environment } \\
\text { and their own family } \\
\text { and community. } \\
\text { Foreign org. are } \\
\text { merely concerned } \\
\text { with their mission and } \\
\text { execution efficiency. }\end{array}$ \\
\hline $\begin{array}{l}\text { "Solution- } \\
\text { Technology }\end{array}$ & $\begin{array}{l}\text { The construction } \\
\text { method and } \\
\text { technology you use } \\
\text { require machine to } \\
\text { complete the task. It's } \\
\text { too expensive; we } \\
\text { can't afford it. }\end{array}$ & $\begin{array}{l}\text { We've well planned the } \\
\text { project; we just want to } \\
\text { complete the task } \\
\text { systematically, fast and } \\
\text { efficient. Why are you } \\
\text { dragging your feet? Why do } \\
\text { you disregard the plan and } \\
\text { are reluctant to } \\
\text { communicate? }\end{array}$ & $\begin{array}{l}\text { The wisdom of local } \\
\text { life technology can } \\
\text { effectively solve the } \\
\text { local construction } \\
\text { problems. Foreign } \\
\text { org. depend more on } \\
\text { modern construction } \\
\text { technology. }\end{array}$ \\
\hline
\end{tabular}

\subsection{Organizational formation of transnational philanthropic entrepreneurship}

In response to the nature of local problems, the transnational team will collect the required technology and social resources and solve the problems at local level with the social connections of local organizations. Even in the process of problem solving, it is inevitable to encounter the above-mentioned challenges in crossorganizational conceptual communications. They can still ultimately solve the problems with patience and the height of ideals by providing mutual coordination and adaptations and gradually establishing the interaction mode of mutual trust.

However, once the problems are solved, the product and service of solution become the inherent demands of the local populace, or even become a feasible commoditized product; then it calls for formal administration and management. The local organizations can take advantages of community connection and easily exercise their influences of administrative management. On the contrary, the international organizations uphold the ideals of service and social welfare; they can only exert indirect influence through the perspective of persuasion. The ownership or jurisdiction over the organization founded by the international philanthropic entrepreneurship between local team and international team formed a dynamic relationship. 


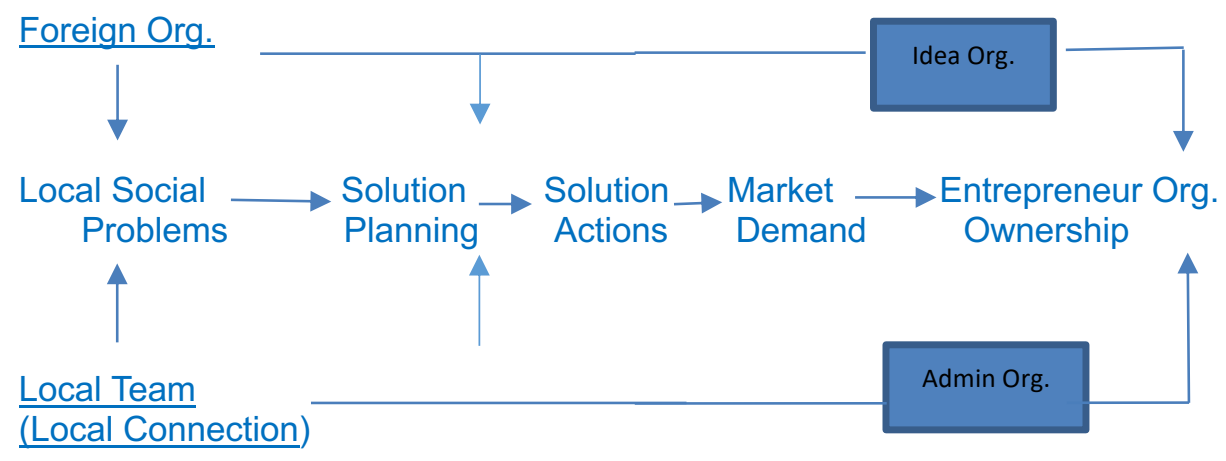

Figure 4. The dynamics of the transnational philanthropic entrepreneurship organization

\section{CONCLUSION}

Either the overseas services by the philanthropic organizations or the overseas insight travel by young people, people have more opportunities to recognize the needs of the foreign under-developed societies, participate in the planning of improving local living conditions, and engage in-person communication with the local groups. The brief exchange of concept gradually developed into actual physical engagement and even discovery of the needs for local business opportunities and entrepreneurship.

Based on the strength of the owned resources, entrepreneurs design the appropriate resource obtaining models for the enterprises to effectively enter the market. The process of social entrepreneurship can adopt very flexible design, choose the management designs fit for various resource capacities, and moderately adopt local concepts and technology to reduce investment risks and effectively leverage the advantages of resources.

When the focus of management gradually shifted from learning, technology transfer, inter-organizational collaboration, delegation (devolution), and joint development (co-development) to inner organizational cross-cultural and intellectual integration, social entrepreneurship organizations must face the challenges of inner dynamic coordination and the integration of international and local resources to strive for a balanced and cooperative use of the social resources and business resources.

The study learned from practical engagement that the transnational philanthropic operation and delivery requires the attitude of pluralism and postmodernism to integrate the own modern mentality and technology with the local wisdom and the technology in use to inspire innovative technology and solve the local problems effectively. 


\section{REFERENCE}

Bornstein, D., 2007. How to Change the World: Social Entrepreneurs and the Power of New Ideas, New York: Oxford University Press.

Den Hond, F. \& De Bakker, F.G.A., 2007. Ideologically motivated activism: How activist groups influence corporate social change, Academy of Management Review, 32, pp. 901924.

Den Hond, F., De Bakker F.G.A. \& J. Doh, 2015. What Prompts Companies to Collaboration with NGOs? Recent Evidence from the Netherlands, Business \& Society, 54(2), pp.187-228.

Emerson, J. \& Fay T., eds., 1996. New Social Entrepreneurs: The Success, Challenge and Lessons of Non-Profit Enterprise Creation. San Francisco, Roberts Foundation, Homeless Economic Development Fund.

Ghemawat, P., 2014. Global Problem Solving Without The Globaloney, Stanford Social Innovation Review, Fall, pp.3-13.

Guclu, A., Dees, G. \& Anderson, B.B., 2002. The Process of Social Entrepreneurship: Creating Opportunities Worthy of Serious Pursuit, Article published by the Center for the Advancement of Social Entrepreneurship, Version: (A) 10/24/02, pp.1-15, Duke University.

Hillman, A.J., Withers, M.C. \& Collins, B.J., 2009. Resource dependence theory: Journal of Management Review, 35, pp.1404-1427.

Joutsenvirta, M., 2011. Setting boundaries for corporate social responsibility: Firm NGO relationship as discursive legitimation struggle. Journal of Business Ethics, 102(1), pp.5775.

Le Ber, M.J. \& Branzei, O., 2010. (Re)forming strategic cross-sector partnerships: Relational processes of social innovation. Business \& Society, 49, pp.140-172.

Letts, C.W. and R.W. Grossman, 1997. Virtuous capital: what foundations can learn from venture capitalists, Harvard Business Review Mar-Apr, 75(2), pp.36-44.

Lucea, R., 2010. How we see them versus how they see themselves: A cognitive perspective of firm-NGO relationships. Business \& Society, 49(1), pp.116-139.

OECD, 1999. Social Enterprises, OECD.

OECD, 2002. Social Enterprises, OECD.

Prahalad, C.K. and A. Hammond, 2002. Serving the world's poor, profitably, Harvard Business Review, September, pp.4-11.

Room, G.J., 1999. Social exclusion, solidarity and the challenge of globalization, International Social Welfare. 8, pp.166-174.

Sen, A., 1993. Markets and freedoms: Achievements and limitations of the market mechanism in promoting individual freedoms, Oxford Economic Paper, 45(4), pp. 519-541. 
Wagner, L., 2002. The "new" donor: Creation or evolution? International Journal of Nonprofit and Voluntary Sector Marketing, 7(4), pp.343-352.

Yaziji, M. \& Doh, J., 2009. NGOs and corporations. Conflict and cooperation. Cambridge. UK: Cambridge University Press. 